\title{
Short pulse laser-induced optical damage and fracto- emission of amorphous, diamond-like carbon
}

\author{
K. Sokolowski-Tinten and D. von der Linde \\ Institute for Laser-and Plasmaphysics, University of Essen, 45117 Essen, Germany \\ Phone:+49-201-183-2570, Fax: +49-201-183-2120, e-mail: kst@ilp.physikuni-essen.de \\ M.P. Siegal and D.L. Overmyer \\ Sandia National Laboratories, Albuquerque, NM 87185-1421, USA
}

\begin{abstract}
Short pulse laser damage and ablation of amorphous, diamond-like carbon films is investigated. Material removal is due to fracture of the film and ejection of large fragments, which exhibit a broadband emission of microsecond duration. C1999 Optical Society of America

OCIS Codes: 350.0350 Other areas of optics, 350.1820 Damage, 320.0320 Ultrafast optics, 320.7130 Ultrafast processes in condensed matter, including semiconductors.
\end{abstract}

Ablation of solids by ultrafast lasers attracts increasing interest, in particular with respect to potential applications of such lasers in material processing. In a number of experiments advantages of ultrashort pulses have been demonstrated, however the understanding of the fundamental physical processes is still incomplete. For semiconductors and metals we have shown recently [1] that near-threshold ablation with ultrashort laser pulses exhibits a material-independent, universal behavior. Removal of material is brought about by hydrodynamic expansion of the laser-generated hot, pressurized matter followed by decomposition into a two-phase, liquid-gas mixture.

In this work we concentrate on the distinct ablation behavior of a specific material system, namely thin films of amorphous, diamond-like carbon. $50 \mathrm{~nm}$ films with densities close to that of crystalline diamond have been grown on quartz and silicon substrates by nanosecond pulsed laser deposition (PLD) [2]. Ablation is initiated by irradiating the surface with single $120 \mathrm{fs}$ laser pulses at $620 \mathrm{~nm}$. An example of the typical surface morphology after irradiation is depicted in the microscope picture in the left part of Fig. 1.
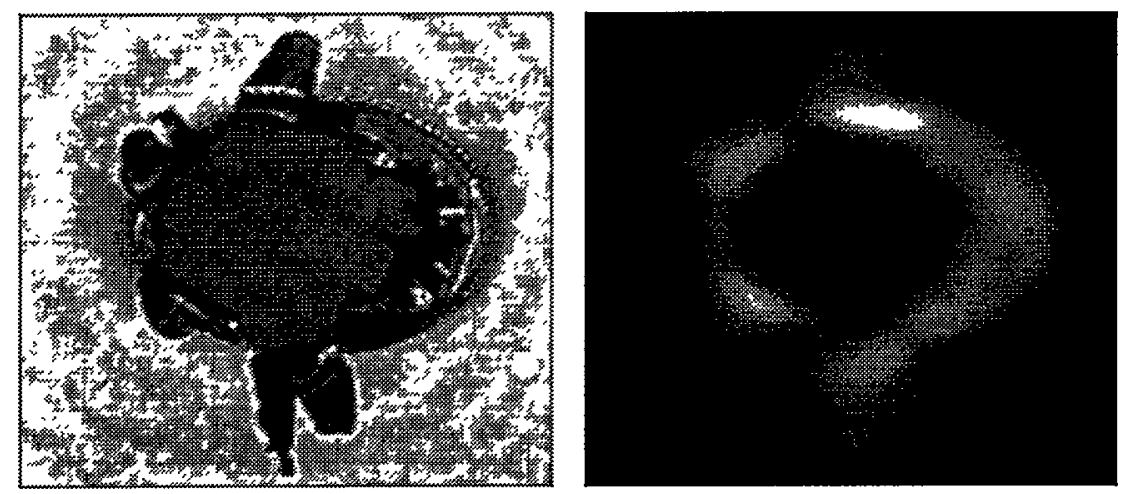

Fig. 1: Left: Microscope image of the final surface morphology after fs-laser irradiation; right: image of the surface obtained with the light which is emitted by the ejected fragments.

Obviously laser irradiation in this case does not lead to a phase transformation of the excited material to the gas phase. Instead the visual impression of the final surface morphology indicates mechanical fracture as the damage mechanism. This process exhibits a well-defined fluence threshold of $220 \mathrm{~mJ} / \mathrm{cm}^{2}$. Near the threshold, at the periphery of the crater, the material seems only lifted from the substrate and forms a periodic surface structure. For higher fluences the film is completely removed, and large fragments, tens of $\mu \mathrm{m}$ in size, are ejected and deposited in and around the ablation region. As can be seen in the left part of Fig. 1 these fragments are the source of a strong optical emission (visible to the bare eye!). Preliminary measurements with different color filters show that the emitted light covers a broad spectral range (from the 


\section{DISCLAIMER}

This report was prepared as an account of work sponsored by an agency of the United States Government. Neither the United States Government nor any agency thereof, nor any of their employees, make any warranty, express or implied, or assumes any legal liability or responsibility for the accuracy, completeness, or usefulness of any information, apparatus, product, or process disclosed, or represents that its use would not infringe privately owned rights. Reference herein to any specific commercial product, process, or service by trade name, trademark, manufacturer, or otherwise does not necessarily constitute or imply its endorsement, recommendation, or favoring by the United States Government or any agency thereof. The views and opinions of authors expressed herein do not necessarily state or reflect those of the United States Government or any agency thereof. 


\section{DISCLAIMER}

\section{Portions of this document may be illegible in electronic image products. Images are produced from the best available original document.}


blue to the near-infrared). The emission is directly related to the fragmentation process, but occurs after deposition of the fragments on a $\mu$ s-time scale, as confirmed by explicit time-dependent measurements. Therefore, simple thermal emission due to laser heating could be ruled as an explanation because this should be strongest just after the excitation when the temperature of the material is highest.

We believe that the peculiar damage behavior is related to the high internal stresses of the films due to the PLD-growth process [3]. Impulsive heating with an ultrashort laser pulse sufficiently reduces the adhesion forces and the film is removed from the subtrate without phase transition to the gas phase. Relaxation of the internal stresses leads then to destruction of the film, ejection of the fragments and the $\mu$ s emission. To our knowledge this is the first observation of the so-called fracto-emission or triboluminescence [4] at the surface of a laser-irradiated material. It should be noted that for higher fluences, above $\approx 400 \mathrm{~mJ} / \mathrm{cm}^{2}$, we do not observe fragmentation and fracto-emission, but the material-independent universal ablation behavior reported in [1].

This work was supported in part by Sandia National Laboratories, US DOE under contract No. DE-ACO494AL85000.

[1] K. Sokolowski-Tinten, J. Bialkowski, A. Cavalleri, D. von der Linde, A. Oparin, J. Meyer-ter-Vehn, and S.I. Anisimov, "Transient States of Matter during Short Pulse Laser Ablation ", Phys. Rev. Lett. 81, 224-227 (1998).

[2] M.P. Siegal, L.J. Martinez-Miranda, H.J. DiNardo, D.R. Tallant, J.C. Barbour, and P. Newcomer Provencio, "Characterization of amorphous carbon films grown by pulsed-laser depostion", in High Power Laser Ablation, C.R. Phipps, (ed.), Proc. SPIE 3343, 885894 (1998).

[3] Y. Lifshitz, S.R. Kasi, and J.W. Rabelais, "Subplanation model for film groth from hyperthermal species: application to diamond", Phys. Rev. Lett. 62, 1290-1293 (1983).

[4] A.J. Walton, "Triboluminescence", Adv. in Phys. 26, 887-948 (1977). 